\title{
Practicability of Application of Re-Engineering the Administrative Processes at Colleges of Education in Universities in Arab-Majority Countries
}

\author{
Bannaga Taha El-Zubair ${ }^{1}$, El-Rusheed Habob Mohammed ${ }^{1}$, Adil Mohammed Dafalla ${ }^{1} \&$ Saad Saleh M. Alqarni $^{2}$ \\ ${ }^{1}$ Faculty of Education, University of Khartoum, Sudan \\ ${ }^{2}$ Faculty of Education, University of Albaha, Kingdom Saudi Arabia \\ Correspondence: Bannaga Taha El-Zubair, Faculty of Education, University of Khartoum, Sudan. E-mail: \\ banagataha@gmail.com
}

Received: June 20, 2020

doi:10.5539/ies.v14n5p87
Accepted: August 23, $2020 \quad$ Online Published: April 26, 2021

URL: https://doi.org/10.5539/ies.v14n5p87

\begin{abstract}
The study aims to highlight the importance of considering the implementation of process of re-engineering Reengineering Administrational Processes (RAP) in the Arab countries universities, particularly, colleges of education to attain good educational outputs. It seeks to highlight the requirements for this implementation and explore the problems associated to the implementation it and distinguish themselves from other organizations is. The Process of Re-Engineering (RAP) is defined as a rapid and drastic re-designing of managerial and strategic process of values at colleges of education in the Arab States Universities in order to attain good educational outputs. The managerial process includes planning, organization, control, follow-up, evaluation and decision taking. The significance of the study is that it can considerably help improve administrative processes applied in the domain of strategic planning at colleges of education in Arab States. The main objective of the study was to outline the main demands of colleges of education for using (RAP) and the obstacles that face its application. For that purpose, the descriptive/ analytic method was used. The study relied heavily on the analysis of the available literature, writings, and publications on the topic, for predicting the practicability of applying RAPRAP. The study came up with the following main results: RAP application, if used properly, can raise the level of job satisfaction among staff members of Arab States colleges of education in particular and the Arab States Universities in general. RAP application can affect total amendments on colleges of education administrative systems for better rendered services. The most demanding requirements of RAP are those that directly relate to the organization structure of the particular corporation, and all its activities for more flexibility, speed and accuracy of performance. The basic human requirements for RAP application include effective training for trainers for the sake of radical change in concepts and ideas. The main obstacles that face RAP application include the poor outcome at colleges of education regarding teaching/learning process, in addition to poor strategic information management on the part of colleges of education and universities. RAP is not fully made use of, despite large sums of money having been spent on for that exact purpose.
\end{abstract}

Keywords: RAP, colleges of education, the Arab-majority countries

\section{Introduction}

The re-engineering of administrational processes (RAP) is considered one of the developmental approaches which is mainly concerned with rapid and radical re-designing of strategic management processes. It equally relates to organizations, policies and organizational structures. It strives towards the improvement with regard to quantity and quality for the sake of maximum satisfaction of customers (Al-Garyouti, 2000, p. 54).

RAP is also sought as an approach for management when rapid and radical changes are occurred for further development and improvement based on performance measures (Davies \& Ellison, 2001, p. 74). To be more effective, development and improvement are considered through a continuous re-designing of the basic strategic processes, policies, organizational hierarchies, values and hypotheses in an untraditional way. In addition, this process must be to correlated harmony with the functional and horizontal integration within a particular institution or organization (Al-Diyyen, 2013, p. 96). RAP, therefore, is likely to be the most effective tool to be used to achieve objectives in several levels such as objectives of institution/organization and staff. Well-planned 
educational decisions that ensure economy in cost and time and attain high outputs, would allow reaching this end. This is specifically what has stimulated the researchers to embark on this study.

\section{The Objectives and Questions of the Study}

Higher education institutions nowadays are facing many problems and challenges in the globalized world in which we live. With all the information and technological challenges and their reflections, most management techniques and methods need to be significantly altered. This situation necessitates new administrative and managerial visions that enable them to increase their efficiency on one hand, and that the quality of outputs be up to the standards of development on the other hand. It could be argued that RAP represents an important call for more creation and innovation in management. It shows that the time to take off repetition and routine in work is indeed approaching. Rethinking and re-designing the main relevant processes in an organization or institution. Moreover, there is demand for taking proper educational decisions relate to the provided service, quality, cost and speedy achievement.

This study primarily aims to highlight why it is important for universities in the Arab countries need to consider the application of RAP within their colleges of education. Part of this, they must understand the requirements for such application. The study also aim to explore the main problems that might face colleges of education when try to apply this concept.

Emerging for above discussion and aims, the problem of the present study focuses on the main question: what is the real state of reengineering of the administrational processes RAP in colleges of education in the Arab-Majority Countries?

The following sub-questions were also stemmed:

1) What are the demands of colleges of education in the Arab States universities for RAP application?

2) What are the requirements of RAP application in colleges of education in the Arab States universities?

3) What are the main problems that face RAP application in colleges of education in the Arab States universities?

\section{The Significance of the Study}

The significance of the study can be characterized in enriching research and knowledge in the domain of RAP and its requirements, and its relationship with performance in colleges of education in the Arab States Universities due to an observed scarcity in studies and writings on the topic. This can open horizons and avenues for more genuine and robust research in that area. The study, designed as such, will help considerably to make use of RAP in the field of strategic planning at colleges of education in the Arab States Universities. The study can be of great use to the managerial staff with regard to the design of sound future planning, implementation and follow-up models.

\section{Methodology}

The researchers used an analytical method to explore the relevant educational Arabic language-based and international literature and scholarly work. For that purpose, an analysis of publications in view of the contemporary global trends in higher education administration literature concerning the RAP application process.

\section{Study Limitations}

The study was specifically narrowed to include higher education institutions, specifically colleges of education, in the universities in the Arab countries. It was also limited to the extent of how the application of the RAP is practicable and could be considered in such colleges as part of their management practices and processes. Additionally, the study was based on the literature review, particularly, in Arabic language scholarly work during the academic year January 2019 to June 2019.

\section{Definitions of Terms}

\subsection{Business Process Re-Engineering RAP}

This is a rapid and drastic re-designing of managerial and strategic process of value. It also relevant to reflect some sort of re-designing the system including some or all of its policies and the other related supporting organizational structures seeking a significant growing of the work flow and promoting its productivity (Mursi, 2003 , p. 125). However, in this study, the research look at the RAP is, as a managerial approach that is based on creating proper techniques to affect drastic changes in all managerial processes in colleges of education in the Arab countries universities, in an attempt to improve the final educational outputs. 


\subsection{Business Processes}

In the current study, these are considered as a process that includes important principles of management such as planning, organization, collaboration, control, follow-up, evaluation and decision-making.

\section{Theoretical Framework and Previous Studies}

\subsection{The Concept of Re-Engineering Administrational Process RAP}

RAP is a newly introduced concept due to merging management with computer sciences. This led to what is commonly known as management information. Consequently, the concept has been widely spread to include institutions in general and educational systems in particular. The concept dates back to 1993 when the two scientists Hammer and Champy published their book titled Re-Engineering the Corporation. They are meant both to boost and activate corporations of different sorts. RAP is a revolution of abandoning all, which is old. It is not a process of re-structuring of ongoing processes, but a total change of them. In other words, it is a new look to all activities, procedures and strategies adopted by most corporations and institutions. RAP is wholly tailored to suit the technological revolution (Hannouna, 2010, p. 23).

\subsection{Principles of RAP (Gawi, 2007, p. 87)}

- Clear specification of the corporation objectives and strategies.

- Re-thinking in the present time and re-discovery of the corporation.

- The inclusion of different functions in one, in view of tasks and not results.

- The execution of work according to its nature through the natural flow of work.

- Getting information from real sources.

- Decreasing the levels of control and audit with stress on the daily control of work.

- Customers are considered the controlling power of objectives and strategies.

- Concentration should be on operations and processes, and not on functions and individuals.

- Corporation should be seen as a comprehensive whole (processes, policies, organizational structures).

- Realizing the supporting value-added processes.

- Making available information and data for the sake of the right taking of decisions.

\subsection{The Requirements of RAP Application in Colleges of Education}

According to Gawi (2007, p. 123), the main RAP requirements in colleges of education are as follows:

Firstly: Organizational Requirements

They are essential requirements of re-engineering the organizational structure of the particular corporation and all its activities for greater flexibility, speed and accuracy of performance. Such re-engineering is necessary for striking the balance between the targeted objectives and other associated activities.

Secondly: Human Requirements

These include the good preparation of trainers to affect the desired radical change in ideas and concepts. They are also necessary to qualify and convince individuals responsible for training in the particular corporation in order to appreciate the idea of re-engineering, and participate in its implementation. This necessitates the explanation of RAP merits for individuals at the particular corporation in the long run. It is also of the utmost importance that the organizational culture should be widely spread among individuals, as with all sorts of adaptation with re-engineering and total quality management. It is also important to able to join one's own directed team work groups, as is the development of the individuals` sense of the client service.

\section{Thirdly: Material Requirements}

These include making available all the funds necessary to achieve the objectives of the corporation. There is also a need to design the effective systems of salaries and incentives, and the work environment needs to be reasonably rehabilitated in respect of location, design, area, internet, and distance communications. If such requirements are met, more time will be saved, and effort and cost will be decreased.

\subsection{Demands of Colleges of Education for RAP Application}

According to Al-Louzi (2002, p. 36), significant benefit could be gained from applying RAP:

1) Different specialized jobs need to be merged into one job. This necessitates that such jobs be located in one 
place for reasons of saving time, and decreasing the cost, as well as coordinating and organizing business.

2) Work tasks can be transferred from being simple to more complex, and this will create a common sense of responsibility among all individuals in the corporation.

3) An increase in the degree of autonomy on the part of all individuals working at the corporation as they are performing their specialized jobs. This will eventually lead to more initiative, creativity and discovery.

4) Encouraging continuous education which is linked with training for more development of skills and competences.

5) Rewarding individuals according to their final and collective results of performance.

6) Changing the traditional culture in such a way that good performance and customer service will be the main priorities.

7) Breaking down obstacles between all levels of management by creating room for all to participate in decision making instead of limiting that to directors alone.

\subsection{Reengineering Processes and Their Relationship with Planning}

Firstly: There is a close link between planning and the process of re-engineering in that

They are both concerned with setting performance scales to judge the quality of the work being done. Applying the two concepts will decrease the risks that can threaten individuals in the particular corporation in the future. This being so, the main objectives of the corporations can be easily achieved in a short period of time with very high degree of excellence. The collaboration of both processes will considerably help to realize the problems and hindrances the corporation is faced with now and in the future. Future planning can considerably reduce cost and save time (Husain, 2007, p. 152).

Secondly: The Relationship between Organization and RAP

For the effective use of RAP, it has to be stressed that RAP is mainly concerned with the re-organization of work to make it match more with the surrounding business changes. Therefore, there is a need for more competent business leaders with a very high awareness and knowledge of such changes, as well as a deep understanding of the objectives of the corporation. The relationship between organization and RAP is also evident in respect of training through work teams. While, the organization likely helps in selecting the targeted trainees who need more trainings to enhance the qualifications they possess, RAP facilitates the coordination of related processes such as power delegation, responsibilities and work distribution. This also includes a meaningful relationship between the organization and RAP, which might be end to a mutual interaction and flexibility within the corporation. Consequently, some changes will take place in the organization itself without the need for making basic amendments on the organizational chart (Mustafa, 2007, p. 102).

\section{Thirdly: The Relationship between Control and RAP}

The relationship is clear in many different ways. RAP is meant to improve the control system in the particular corporation. It also helps in the clarification of the objective elements of control. It plays a sizeable role in making the control techniques easy to apply for users. It also makes the control system adopted in the corporation more flexible so that it can be amended if the surrounding conditions change. RAP allows more room for using different techniques and tools of control instead of applying only one technique or tool. Both RAP and control are mainly concerned with quality and performance improvement with the aim of achieving qualitative educational outputs.

Fourthly: The Relationship between RAP and Follow-up and Evaluation

Such a relationship becomes clearer as many performance controls are progressively used, such as transparency, accountability and societal control, as well as the specifications of the desired training needs. In addition, RAP is always targeting excellence, creativity assessment and a follow-up of performance from more than one source i.e. performance observation, and an activities and documentation follow-up (Alimat, 2007, p. 54).

Fifthly: The Relationship between RAP and Decision Making

One of the merits of RAP is that it allows more opportunities for individuals working in the corporation to participate in the decision making processes. It also allows for greater satisfaction among individuals and at the same time gives them a chance for leadership training (Al-Riwaily, 2003, p. 78).

\subsection{Problems Facing RAP Application at Colleges of Education}

According to Khaleel (2008, p. 29), colleges of education are inevitably faced by many challenges such as: 
1) The scarcity of information on projects' re-structuring.

2) Employees`resistance seldom contests RAP.

3) The role of individuals in RAP projects is not always clear and poorly felt.

4) The short vision of some corporations.

5) Poor training and rehabilitation of human resources.

6) The concentration on the actual standing situation of the corporation with poor planning for the future.

7) Improper use of information technology.

8) The concept of RAP is not fully unified.

9) The hastiness to attain results which in turn leads to little improvement to what is actually available.

10) The inability to get rid of traditional managerial systems and practices.

11) The belief of RAP leaders that their role is complete once they take decisions.

12) The pre-set theoretical framework and working according to it.

13) Unrealistic expectations from RAP results and outputs.

14) The limited benefit from external experience and expertise.

\section{Previous Studies}

Studies that are addressing RAP are many, and their results are varied. In what follows are some of the studies that the researchers have reviewed.

The study of Al-Digni (2013) sought to set a proposed model for a computerized RAP in higher education institutions (The Islamic University in Gaza- a case study). The study came up with the following main results: Efforts to document work guides and simplification of work processes were not effective enough before RAP applications. Generally, there is a reasonable degree of acceptance among individuals of RAP as it succeeded in achieving favorable results as far as the work organization is concerned. In addition to that, RAP application, according to many, has increased the level of job satisfaction among employees.

Yusif (2014) highlighted RAP techniques and put great emphasis on the significance and need for RAP in Egyptian universities. It has also been proposed that there is a need for a framework for RAP, as one of the organizational change approaches. According to the study of Abdou (2008) the objective was to propose at a proposed model for RAP in higher education institutions. A four-step serialized framework was proposed.

Also, Reehan (2014) conducted a study to understand the obstacles face the application of RAP in public schools in Gaza province in an endeavor to solve or at least alleviate them. The results of the study revealed that there was a high degree of agreement among school directors that such obstacles were real. In Al-Shobaky's (2010) study, the main objective was to realize the relationship between decision support systems and RAP in Palestinian Universities in the Gaza Strip. A descriptive/analytical method was used. The study came up with following main results: There is an intimate relationship between decision support systems and RAP in Palestinian universities in the Gaza Strip attributed to the (University Variable) in favor of the Islamic university. There were differences of statistical significance between the sample members' responses with regard to the relationship decision support systems and RAP according to the university variable.

In his study to explore the degree of RAP application in university colleges in Gaza and its relationship with educational output quality, Abu Salim (2016) used a descriptive/analytical method. He reached that the degree of RAP application in university colleges in Gaza was relatively high, at $7.34 \%$. Additionally, in the study of Obi and Ibezim (2013), the purpose was to estimate the degree of the Nigeria experience of using RAP. Despite the big sums of money spent on investments in information management in the universities, the outcome regarding the teaching and learning processes, and the university management as a whole, was considerably low as the strategic information management was not apparently made use of fully.

Finally, Sinhato and Singh (2012) analyzed RAP processes in the Ethiopian higher education institutions in order to assess the degree of its application effectiveness applications. He found that the performance of higher education institutions was not highly effective in terms of achieving institution's objectives through a proper application of the RAP. One of the study's conclusions is that the development in higher education institutions was far less than expected. 


\section{Results of the Study}

1) RAP application, if properly used, will raise the level of job satisfactions among staff members of colleges of education in particular, and the universities as a whole.

2) RAP application has led to essential amendments in colleges of education management systems whenever RAP requirements were met and adhered to for the sake of better services.

3) RAP is one of the recently introduced approaches which is mainly concerned with rapid and radical re-designing of a value-added strategic management processes.

4) RAP is an effective tool for inducing changes in all management processes for the sake of more improvements in view of the basic performance scales.

5) If properly applied, RAP will undoubtedly contribute to a better and a more full understanding, and thereafter, achieving objectives on both university and staff levels through carefully planned decisions reflecting the requirements of effectiveness and efficiency in terms of costs and time.

6) One of the most demanding RAP requirements is that directly relevant to the practice of corporation and its related-activities in an organization. Such practice would allow more flexibility, rapidity and performance accuracy.

7) Good and well-planned preparation of trainers is an essential element to affect the desired radical change in ideas and concepts of the corporation.

8) Work tasks in the corporation, if transferred from being simple to more complex, will create a common sense of responsibility among all individuals in the long term.

9) Different specialized jobs, if merged into one job and one place, will save time and cost, also helps coordinate and organize business.

10) If more autonomy is given to employees of the corporation, more initiative, creativity and discovery will be attained.

11) Changing traditional organizational culture in a way that should be the main priority.

12) Efforts to document work guides of the simplification of work processes in most colleges of education are not effective enough prior to RAP applications.

13) Despite the substantial amount of money to invest in the information technology management in universities, particularly in colleges of education, the outcome of not only the teaching and learning but also university management is considerably low.

\section{Recommendations of the Study}

1) RAP application will be more effective in colleges of education if there is a comprehensive evaluation and analysis of all current situations and the ensuring of full support of the higher administrative levels, as well as making available the necessary requirements of RAP.

2) There is a need for more spreading and enforcement of RAP concept itself among individuals working in the corporation at colleges of education and universities.

3) Workshops need to be regularly held alongside specialized training courses in recent management systems, and making the individual more aware of their work tasks in order to attain a high degree of competence.

4) Regular revision of the corporation organizational structure needs to be done to get rid of work duplication and unnecessary routine; this is to be safeguarded by continuous control.

5) Colleges of education are required to keep up with the more recent international developments in the field of administrative practice.

6) Good preparation of work teams should be encouraged for reasons of affecting radical change of ideas and concepts. This needs to be coupled with the use of new technology.

7) Material and financial requirements should be regularly made available. This necessitates new technological infrastructure, more funds, and donations and grants given by local civil organizations.

\section{References}

Abdous. H. A. (2008). A Frame Work for Process Re-Engineering in higher Education: A Case Study of Distance Learning Exam Scheduling and Distribution. The International Review of Research in Open and Distance Learning, 9(3), 1492-3831. https://doi.org/10.19173/irrodl.v9i3.535 
Abu Salim, A. M. (2016). The Degree of Applying Business Process Re-Engineering in University Colleges in Gaza and its relationship with Educational outputs Quality (Unpublished M.A. dissertation). College of Education, Islamic University, Gaza.

Al-Digni, I. S. (2013). A Suggested Model for Business Process Re-Engineering and its Computerization in Higher Education Institutions (The Islamic University: A Case Study). Damascus: Damascus University Press.

Al-Diniyeen, M. B (2013). The Degree of Use Public Schools` Directors in Kuwait of Business Process Re-Engineering and its Relationship with their Practice of Administrative Creativity from Teachers ' Perspective (Unpublished M.A. dissertation). Jordon: College of Education, Middle East University.

Al-Gartouti, M. A. (2000). Behavioral Organization, A study of Individual and Mass Human conduct in Various Corporations. Amman: Al-Shuroug House for Publication and Distribution.

Alimat, S. S. (2007). Administrative Processes in Educational Institutions. Ramalla: Al-Shrioug for Publication and Distribution.

Al-Khaleel, A. B. (2008). The Role of Re-Engineering in Boosting Cost Decrease Decisions in View of Change Management Philosophy. A working Paper Submitted to the Eighth Annual Internal Scientific Conference: Change Management and Knowledge Society, 21-24 April, College of Economics and Administration Sciences, Al-Zaitouna University, Amman, Jordon.

Al-Louzi, M. Y. (2002). Organization and Work Procedures. Amman: Al-Wael Publishing House.

Al-Riwaile, M. J. (2003). Educational Leaders' Perspectives in Saudi Arabia on how Available are the Elements of Effective school Management and its Future importance with Reference to their Attitudes towards Organizational Development and Change (Unpublished Ph.D. thesis). University of Yarmouk, Irbid, Jordon.

Al-Shobaky, M. N. (2016). The Relationship Between Decision Support Systems and Business Processes Re-Engineering in Palestine Universities in Gaza Province (Unpublished M.A. Dissertation). Al-Azhar University, Gaza, Palestine.

Davies, B. M., \& Ellison, L. K. (2001). Organizational learning: Building the Future of a School. International Journal of Educational Management, 15(2), 78-85. https://doi.org/10.1108/09513540110383809

Gawi, B. H. (2007). Re-Engineering University Performance: A New Look. Al-Bahith Journal, 5, 137-145.

Hammer, M. H., \& Champy, J. W. (1993). Reengineering the Corporation. Harper Collins Inc., New York.

Hannown, N. L. (2010). The Degree of business Process Re-Engineering Use in the Administrative Practice in Public Schools in the West Bank from the Directors perspective (Unpublished M.A. thesis). Al-Najah National University, Naples, Palastine.

Husain, S. G. (2007). Business Process Re-Engineering Revolution: A New Approach to Educational Systems. Alexandria: New University House.

Mursi, J. A. (2003). The Strategic Management of Human Resources. Alexandria: University House.

Mustafa, Y. R. (2007). Educational Administration: New Approaches for a New World. Cairo: Al-Fikr al-Arabi house.

Obi, C. A., \& Ibezim, N. M. (2013). Re-Engineering University Education Through StrateficInformatin Management: The Nigerian Experience. Scientific Research (pp. 783-800). https://doi.org/10.4236/me.2013.411083

Reehan, S. K. (2014). Business Process Re-Engineering Application Obstacles in Public Schools in Gaza Province (Unpublished M.A. dissertation). College of Education, Islamic University, Gaza, Palestine.

Sibhato, H. L., \& Singh, A. K. (2012). Evolution of Implementation in Ethiopian Higher Education Institutions. Global Journal of Management and Business Research, 12(11), 1-29.

Yusif, D. M. (2014). A Suggested Framework for the Use of Business Process Re-Engineering as an Approach for Organizational Change in Egyptian Universities in view of some Countries Experience. 


\section{Copyrights}

Copyright for this article is retained by the author(s), with first publication rights granted to the journal.

This is an open-access article distributed under the terms and conditions of the Creative Commons Attribution license (http://creativecommons.org/licenses/by/4.0/). 